\title{
Contribuição da imuno-histoquímica na avaliação de fatores prognósticos e preditivos do câncer de mama e no diagnóstico de lesões mamárias
}

Primeira submissão em 27/02/09 Última submissão em 27/02/09 Aceito para publicação em 04/06/09 Publicado em 20/06/09

\section{Contribution of immunohistochemistry to the assessment of prognostic and predictive factors of breast cancer and to the diagnosis of mammary lesions}

Marcio de Almeida Salles ${ }^{1}$; Vinícius Silva Cúrcio²; Amanda Arantes Perez³; Douglas Soltau Gomes; Helenice Gobbi ${ }^{5}$

unitermos
Mama
Carcinoma
Diagnóstico
Patologia
Imuno-histoquímica
Fatores preditivos

\section{resumo}

Objetivo: Fazer análise crítica da contribuição da imuno-histoquímica na avaliação de fatores preditivos/ prognósticos do câncer de mama, na pesquisa de micrometástases em linfonodos sentinela e no diagnóstico diferencial de lesões mamárias. Métodos: Foi realizado estudo observacional retrospectivo de todos os casos de lesões mamárias e linfonodos sentinelas submetidas a estudo imuno-histoquímico no Laboratório de Patologia Mamária da Faculdade de Medicina da Universidade Federal de Minas Gerais (UFMG) entre 2001 e 2007. Os casos foram classificados de acordo com a indicação do estudo imuno-histoquímico em três categorias: avaliação de fatores preditivos/prognósticos, pesquisa de células epiteliais metastáticas em linfonodos sentinela e definição diagnóstica. Resultados: Foram realizados exames imuno-histoquímicos de 1.294 casos, totalizando 4.101 reações com 21 anticorpos diferentes. Na maioria dos casos, a imuno-histoquímica foi realizada para avaliação de fatores preditivos/prognósticos (1.106 casos, 85,5\%), seguido de pesquisa de células epiteliais metastáticas em linfonodos sentinelas (134 casos, 10,6\%) e diagnóstico diferencial de lesões mamárias (51 casos, 3,9\%). Obtiveram-se reações de boa qualidade com importante contribuição do estudo imuno-histoquímico em 1.247 casos (96,4\%). Em 47 casos (3,6\%), o resultado foi inconclusivo devido a problemas de fixação (autólise) da fase préanalítica. Conclusão: Nossos dados confirmam ser o estudo imuno-histoquímico importante ferramenta para avaliação de fatores preditivos e prognósticos do câncer de mama, pesquisa de micrometástases em linfonodos sentinelas e diagnóstico diferencial de lesões mamárias. A maior utilização da imunohistoquímica foi para avaliação de fatores preditivos e prognósticos do câncer de mama

\section{abstract}

Objective: To critically analyze the contribution of immunohistochemistry to the assessment of prognostic and predictive factors of breast cancer, to the search for micrometastases in sentinel lymph nodes, and to the differential diagnosis of mammary lesions. Methods: An observational retrospective study was carried out reviewing all cases of mammary lesions submitted to immunohistochemistry at the Breast Pathology Laboratory of Federal University of Minas Gerais between 2001 and 2007. According to immunohistochemistry indication, the cases were classified into three categories: assessment of prognostic and predictive factors, search for epithelial metastatic cells in sentinel lymph nodes and differential diagnosis. Results: Immunohistochemistry was performed in 1,294 cases, with 4,101 reactions using 21 different antibodies. In most cases, immunohistochemistry was conducted to assess predictive/prognostic factors $(1,106$ cases, $85.5 \%)$, followed by search for epithelial metastatic cells in sentinel lymph nodes (134 cases, 10.6\%) and differential diagnosis of breast lesions (51 cases, 3.9\%). Good quality reactions, with significant contribution to the immunohistochemistry study, were obtained in 1,247 cases (96.4\%). In 47 cases (3.6\%) the results were inconclusive due to fixation problems (autolysis) in the pre-analytical phase. Conclusion: Our data confirm that the immunohistochemical study is an important tool to the assessment of predictive and prognostic factors, search for micrometastases in sentinel lymph nodes, and differential diagnosis of mammary lesions. The widest use of immunohistochemistry was in the assessment of predictive and prognostic factors of breast cancer. key words

Breast

Carcinoma

Diagnosis

Pathology

Immunohistochemistry

Prognostic factors

1. Doutorando do Programa de Pós-Graduação em Saúde da Mulher da Universidade Federal de Minas Cerais (UFMG).

2. Bolsista de iniciação cientifica do Conselho Nacional de Desenvolvimento Cientifico e Tecnológico (CNPq).

3. Mestranda do Programa de Pós-Graduação em Saúde da Mulher da UFMG

4. Mestrando do Programa de Pós-Graduação em Patologia da UFMG.

5. Professora associada-doutora da Faculdade de Medicina da UFMG

Laboratório de Patologia Mamária da Faculdade de Medicina da UFMG. 


\section{Introdução}

A imuno-histoquímica (IHQ) teve grande desenvolvimento a partir da década de 1970, quando foi possível demonstrar antígenos teciduais pela técnica de imunoperoxidase em tecidos fixados em formalina e incluídos em parafina. Atualmente, a IHQ está incorporada à patologia cirúrgica como método diagnóstico complementar. $\mathrm{O}$ desenvolvimento de anticorpos monoclonais propiciaram enorme fonte de reagentes altamente específicos para a demonstração de vários antígenos teciduais e celulares, e o advento da recuperação antigênica foi um fato marcante na evolução da $\mathrm{HHQ}^{(3,33)}$.

A IHQ é influenciada por vários fatores, desde a fase pré-analítica (fixação e processamento dos tecidos), passando pela fase analítica (escolha de anticorpos primários e sistema de visualização), até a fase pós-analítica (interpretação dos resultados). A experiência do patologista com o método é fator relevante, pois ele interfere na escolha dos reagentes e anticorpos a serem usados em cada caso, analisa a qualidade das reações e interpreta os resultados da coloração. Além disso, o patologista integra os achados morfológicos com os resultados do estudo imuno-histoquímico, formulando o diagnóstico anatomopatológico final $(2,13,30)$.

O estudo imuno-histoquímico tem sido utilizado em diferentes situações da patologia mamária, sendo as mais importantes: avaliação de fatores preditivos e prognósticos do câncer de mama, pesquisa de células epiteliais metastáticas em linfonodo sentinela, diagnóstico diferencial de lesões mamárias e determinação de possível origem de neoplasias metastáticas $(12,13,23,27,28,49)$.

A importância clínica do uso da IHQ foi reconhecida e incorporada pelo sistema público de saúde e por convênios médicos brasileiros a partir da década de 1990, quando foi implantada no Laboratório de Patologia Mamária da Faculdade de Medicina da Universidade Federal de Minas Gerais (UFMG). A IHQ passou a ser realizada rotineiramente na avaliação de fatores preditivos em todos os casos de câncer de mama diagnosticados no Hospital das Clínicas da UFMG a partir de 2000.

No presente trabalho, avaliamos nossa experiência com o uso da IHQ, analisando as indicações do método e sua contribuição em patologia mamária. Os achados são correlacionados com os dados da literatura, discutindo-se aspectos práticos da aplicação da IHQ, fatores limitantes e contribuição da IHQ nessa área da patologia.

\section{Material e métodos}

Foi realizado estudo retrospectivo observacional e descritivo. Foram selecionados todos os casos de lesões mamárias submetidos a estudo imuno-histoquímico no Laboratório de Patologia Mamária da Faculdade de Medicina da UFMG no período de 2001 a 2007. Todos os casos foram inicialmente avaliados por uma mesma patologista (HG) que confirmou a necessidade do estudo imuno-histoquímico e definiu os anticorpos a serem empregados, seguindo hipóteses diagnósticas ou solicitação do exame feito pelo oncologista ou cirurgião.

Foram analisados sexo e idade dos pacientes, proveniência do material, indicação do estudo, tipo de espécime, anticorpos utilizados e resultados das reações. Os anticorpos primários mais empregados, os fabricantes, as diluições e o uso de reativação antigênica estão sumarizados na

\section{Tabela 1.}

A técnica de visualização da reação usada no estudo imuno-histoquímico foi a estrepto-avidina biotina peroxidase (Biogenex, EUA), e a revelação foi feita com diaminobenzidina. Controles positivos e negativos para cada anticorpo utilizado foram incluídos em todas as baterias de coloração.

Os resultados das reações considerados na análise deste trabalho foram aqueles presentes nos laudos imuno-histoquímicos originais, emitidos pela mesma patologista $(\mathrm{HG})$ no período estudado. A análise das reações e a definição dos níveis de positividade foram feitas empregando-se critérios aceitos na literatura internacional e detalhados a seguir. A avaliação dos receptores de estrógeno (RE) e progesterona (RP) foi realizada empregando-se critérios aceitos pela Conferência de Consenso do Colégio Americano de Patologistas (CAP) no período em que as reações foram realizadas ${ }^{(12)}$. O tumor foi considerado positivo quando mais de $10 \%$ das células tumorais mostravam núcleos marcados, independentemente da intensidade da reação ${ }^{(12)}$. Para avaliação do HER2, foram considerados os critérios propostos no manual do Herceptest ${ }^{\circledast}$ e aceitos pela literatura no período de realização dos testes $(8,18,19,31)$. Escolhem-se os campos com maior intensidade de coloração, considerando-se apenas a positividade da membrana celular, desprezando a coloração citoplasmática. O valor zero (negativo) corresponde aos casos em que não se observa coloração ou a coloração da membrana está presente em menos de $10 \%$ das células tumorais; $1+$ (negativo), coloração fraca é percebida em mais de $10 \%$ das células 


\section{Tabela 1}

Anticorpos empregados, clones, fabricantes, diluição e reativação antigênica

\begin{tabular}{lcccc}
\hline Anticorpo & Clone & Fabricante/país & Diluição & Reativação antigênica \\
RE & $6 F 11$ & Novocastra / RU & $1: 100$ & Citrato pH 6 \\
RP & PgR312 & Novocastra / RU & $1: 100$ & Citrato pH 6 \\
HER2 & CB11 & Novocastra / RU & $1: 80$ & Sem reativação \\
p53 & D07 & Dako / EUA & $1: 200$ & Citrato pH 6 \\
AE1/AE3 & AE1/AE3 & Dako / EUA & $1: 100$ & Citrato pH 6 \\
Ki67 & MIB-1 & Imunotech / FR & $1: 50$ & Citrato pH 6 \\
p63 & $4 A 4$ & Dako / EUA & $1: 100$ & EDTA pH 9 \\
Actina m. liso & SA4 & Sigma / EUA & $1: 1000$ & Citrato pH 6 \\
E-caderina & NCH-38 & Dako / EUA & $1: 100$ & Citrato pH 6 \\
EMA & E-29 & Dako / EUA & $1: 100$ & Citrato pH 6 \\
Vimentina & V9 & Dako / EUA & $1: 100$ & Citrato pH 6 \\
D2-40 & D2-40 & Dako / EUA & $1: 100$ & Sem reativação \\
CD31 & JC70A & Dako / EUA & $1: 100$ & Citrato pH 6 \\
CK-HMW & 34 BE12 & Dako / EUA & $1: 100$ & EDTA pH 9
\end{tabular}

RU: Reino Unido; EUA: Estados Unidos da América; FR: França; RE: receptor de estrógeno; RP: receptor de progesterona; HER2: receptor de fator de crescimento epidérmico; actina m. liso: actina de músculo liso; EMA: antígeno de membrana epitelial; CK-HMW: citoqueratina de alto peso molecular. tumorais, com apenas parte da membrana das células tumorais coradas; $2+$ (fracamente positivo) coloração fraca a moderada é observada em toda a extensão da membrana em mais de $10 \%$ das células tumorais e $3+$ (fortemente positivo) coloração moderada a acentuada é observada em toda a extensão da membrana em mais de $10 \%$ das células tumorais ${ }^{(8,12)}$.

Para análise do $\mathrm{p} 53$, foi considerado positivo o tumor com mais de $10 \%$ de núcleos de células neoplásicas coradas pelo marcador ${ }^{(12)}$. A marcação pelo Ki67 (clone MiB-1) foi classificada como alto índice proliferativo (tumores com mais de $25 \%$ de núcleos marcados), índice proliferativo intermediário (tumor com $10 \%$ a $25 \%$ de núcleos marcados) e baixo índice proliferativo (tumores com menos de $10 \%$ de núcleos marcados) ${ }^{(22)}$. Os demais marcadores foram analisados qualitativamente e considerados positivos na vigência de qualquer nível de marcação, independentemente da intensidade da reação.

Quanto à indicação do exame imuno-histoquímico, os casos foram classificados em três categorias: 1) avaliação de marcadores preditivos/prognósticos (Figuras 1A e 1B); 2) pesquisa de células epiteliais metastáticas em linfonodo sentinela (Figura 1C); 3) definição diagnóstica (Figura 1D).

Esse trabalho foi aprovado pelo Comitê de Ética em Pesquisa da UFMG (parecer ETIC 52/08).

\section{Resultados}

No período analisado, foram realizados exames imunohistoquímicos de 1.294 casos, totalizando 4.101 reações, empregando-se 21 anticorpos diferentes.

A idade dos pacientes variou de 18 a 98 anos (média de 53 anos). Os casos foram ainda divididos em dois grupos de acordo com a idade dos pacientes: $<50$ anos (540 casos) e $>50$ anos (754 casos). Cinco casos eram do sexo masculino $(0,38 \%)$ e 1.289 casos $(99,62 \%)$ eram do sexo feminino. Dos 1.294 exames imuno-histoquímicos, 943 (72,87\%) foram oriundos do próprio Hospital das Clínicas da UFMG e 351 exames (27,13\%) foram recebidos em consultoria ou eram exames de pacientes encaminhados para tratamento em nosso hospital.

Quanto ao tipo de material no qual foi empregada a IHQ, 1.132 casos $(87,5 \%)$ corresponderam a lesões mamárias e 162 casos (12,5\%), a linfonodos axilares.

O exame imuno-histoquímico foi realizado em amostra mamária obtida por biópsia incisional, excisional ou tumorectomia em 692 casos (53,5\%), core biopsy em 238 casos $(18,45)$, mastectomia em 299 casos $(23,1 \%)$ e não informado em 65 casos (5\%).

A maioria dos exames de IHQ realizados foi para avaliação de fatores prognósticos e preditivos (1.106 casos, 
85,5\%; Figuras 1A e 1B), seguidos da pesquisa de células epiteliais metastáticas em linfonodos (137 casos, 10,6\%; Figura 1C) e diagnóstico diferencial (51 casos, 3,9\%). A distribuição dos casos de acordo com indicação do exame imuno-histoquímico é mostrada na Tabela 2.

Fizemos 33 reações para avaliação do Ki67: 15 tumores foram considerados de alto índice proliferativo, nove tumores foram considerados de índice proliferativo intermediário e outros nove foram considerados de baixo índice proliferativo.

Tivemos 1.106 casos $(85,5 \%)$ com 3.767 reações IHQ para avaliação dos fatores preditivos e prognósticos, empregando-se de dois a cinco anticorpos/caso (média = 3,4 anticorpos/caso). Para a pesquisa de células epiteliais metastáticas, utilizou-se apenas o anticorpo monoclonal antipancitoqueratina (AE1/AE3), enquanto para definição diagnóstica o número de anticorpos/caso variou de um a oito (média $=3,8$ anticorpos/caso).

As principais utilizações da IHQ no diagnóstico diferencial foram:

- diferenciação de lesões epiteliais proliferativas: carcinoma ductal in situ (CDIS) versus carcinoma lobular in situ (CLIS) em 11 casos (21,5\%); CDIS versus CDIS com microinvasão em sete casos (13,7\%) e hiperplasia atípica ou CDIS de baixo grau versus hiperplasia epitelial (HE) usual em cinco casos $(9,8 \%)$;

- diferenciação entre papiloma versus carcinoma papilífero intracístico em oito casos (15,7\%);

- diferenciação de carcinoma micropapilar invasor (Figura 1D) versus carcinoma ductal invasor com artefatos de retração em cinco casos (9,8\%);

- diferenciação de carcinoma tubular invasor versus cicatriz radial e adenose em três casos (5,9\%);

- identificação de êmbolos linfáticos em cinco casos $(9,8 \%)$;

- identificação de tumores com diferenciação neuroendócrina em três casos (5,9\%);

- diferenciação entre carcinoma metaplásico e sarcoma em quatro casos $(7,8 \%)$.

Alguns anticorpos foram utilizados poucas vezes (43 reações; $1 \%$ ) para o diagnóstico diferencial de lesões mamárias e incluíram: calponina (sete casos), cromogranina (sete casos), enolase específica de neurônio (seis casos), fator de crescimento epidérmico (EGFR[seis casos]), citoqueratina 5/6 (CK 5/6; seis casos), proteína S100 (seis casos) e desmina (cinco casos).

\section{Distribuição dos casos de acordo com os anticorpos empregados e com a indicação do estudo}

Tabela 2 imuno-histoquímico

\begin{tabular}{lccccccc}
\hline $\begin{array}{l}\text { Anticorpo } \\
\text { empregado }\end{array}$ & Fator preditivo/prognóstico & $\begin{array}{c}\text { Pesquisa de células } \\
\text { epiteliais metastáticas }\end{array}$ & Definição diagnóstica & Total \\
RE & + & - & + & - & + & - & \\
RP & 735 & 361 & 0 & 0 & 6 & 5 & 1.107 \\
HER2 & 655 & 430 & 0 & 0 & 4 & 6 & 1.095 \\
p53 & 177 & 807 & 0 & 0 & 0 & 0 & 984 \\
AE1/AE3 & 196 & 373 & 0 & 0 & 0 & 0 & 569 \\
p63 & 0 & 0 & 13 & 124 & 0 & 0 & 137 \\
Actina m. liso & 0 & 0 & 0 & 0 & 18 & 15 & 33 \\
E-caderina & 0 & 0 & 0 & 0 & 20 & 9 & 29 \\
EMA & 0 & 0 & 0 & 0 & 11 & 6 & 17 \\
Vimentina & 0 & 0 & 0 & 0 & 12 & 1 & 13 \\
D2-40 & 0 & 0 & 0 & 0 & 8 & 5 & 13 \\
CD31 & & 0 & 0 & 0 & 2 & 8 & 10 \\
CK-HMW & 0 & 0 & 0 & 0 & 3 & 6 & 9 \\
Total & 1.763 & 1.971 & 13 & 124 & 88 & 66 & 4.025
\end{tabular}

RE: receptor de estrógeno; RP: receptor de progesterona; HER2: receptor de fator de crescimento epidérmico; actina m. liso: actina de músculo. liso; EMA: antígeno membrana epitelial; CK-HMW: citoqueratina de alto peso molecular.

Houve 43 reações com anticorpos menos frequentes e 33 reações com Ki-67. Total de reações: 4.101. 

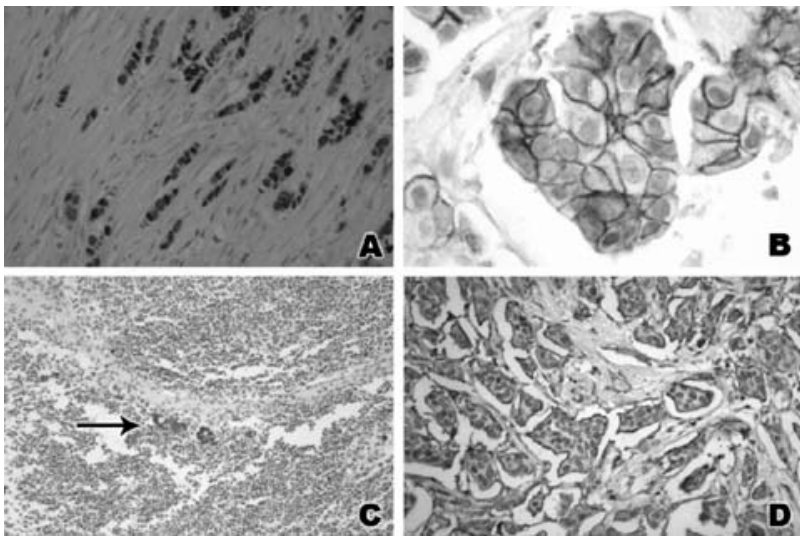

Figura 1 - A: carcinoma lobular invasor apresentando núcleos corados para receptor de estrógeno; B: carcinoma ductal invasor mostrando positividade membranar para HER2; C: células epiteliais isoladas, coradas para citoqueratina (AE1/AE3) em linfonodo sentinela; $D$ : carcinoma micropapilar invasor mostrando micropapilas, com borda epitelial voltada para o estroma corado pelo antígeno de membrana epitelial

Em 47/1.294 (3,6\%) casos, a reação IHQ teve a sua interpretação prejudicada ou impossibilitada. Em 21/47 casos $(44,7 \%)$, havia autólise significativa do tumor, e a negatividade da reação foi relacionada à fixação inadequada. Nestes casos, a negatividade para RE ou RP em lóbulos e ductos mamários normais adjacentes à neoplasia permitiu afirmar que a negatividade das reações estava relacionada com problemas de fixação (fase pré-analítica). Em 18/47 casos $(38,3 \%)$, havia intensa coloração citoplasmática inespecífica relacionada com artefato de compressão da amostra (crash artefact) que prejudicou a análise da reação de marcador membranar (HER2). Em oito casos (17\%) em que a reação foi negativa, havia relato de permanência do material em formol por tempo prolongado (mais de 72 horas sem clivagem do material). Nesses casos, mesmo utilizando recuperação antigênica, essa não foi suficiente para reverter o excesso de fixação e a autólise do material.

Em 1.093 casos, avaliamos a coexpressão dos receptores hormonais e observamos que os tumores eram: $\mathrm{RE}+/ \mathrm{RP}+\mathrm{em}$
624 casos (57\%), RE+/RP- em 105 casos (9,6\%), RE-/RP+ em 33 casos (3\%) e RE-/RP- em 331 casos (30,4\%).

Os 979 casos em que se analisaram receptores hormonais e HER2 foram agrupados em quatro categorias, de acordo com a classificação molecular com base no imunofenótipo dos tumores, como evidenciado na Tabela 3: negativo para os três marcadores em 213 casos (21,8\%), referidos como triplo-negativos; luminal A (RE+ e HER2-) em 590 casos (60,2\%); luminal B (RE+ e HER2+) em 88 casos (9\%) e HER2+/RE- em 88 casos (9\%).

\section{Discussão}

O presente estudo mostrou que a maior utilização da IHQ em um laboratório de patologia mamária, vinculado a um hospital geral de ensino, foi na avaliação de fatores preditivos e prognósticos do câncer de mama ( $85,5 \%$ dos casos). Em outras áreas da patologia, o maior emprego da IHQ é na definição diagnóstica (64\% dos casos) ${ }^{(3)}$. A maior utilidade da IHQ na patologia cirúrgica em geral é como ferramenta complementar no diagnóstico diferencial de tumores indiferenciados, na imunofenotipagem de linfomas e na determinação de origem primária de neoplasias metastáticas de sítio primário desconhecido(3).

O uso da IHQ na avaliação de fatores preditivos em câncer de mama permite identificar pacientes que poderão se beneficiar de tratamentos específicos, contribuindo na decisão terapêutica ${ }^{(1,12,13,33)}$. Os fatores preditivos são características clínicas, patológicas e biológicas usadas para estimar a probabilidade de resposta a um determinado tipo de terapia adjuvante. Alguns fatores podem ser preditivos e prognósticos simultaneamente, como o HER2, enquanto os

Relação entre idade dos pacientes e subtipos de tumores mamários de acordo com a imunofenotipagem molecular (positividade ou negatividade dos tumores para receptores

Tabela 3 hormonais e HER)

\begin{tabular}{lccc}
\hline Imunofenotipagem & Número de casos & $<50$ anos & $>50$ anos \\
molecular & $213(21,8 \%)$ & $93(43,7 \%)$ & $120(53,3 \%)$ \\
Triplo negativo & $590(60,2 \%)$ & $220(37,3 \%)$ & $270(62,7 \%)$ \\
Luminal A & $88(9 \%)$ & $44(50 \%)$ & $44(50 \%)$ \\
Luminal B & $88(9 \%)$ & $34(38,6 \%)$ & $54(61,4 \%)$ \\
HER2+/RE & $979(100 \%)$ & $391(39,9 \%)$ & $588(61,1 \%)$ \\
Total & &
\end{tabular}

RE: receptor de estrógeno; HER2: receptor de fator de crescimento epidérmico. 
receptores hormonais são melhores como fatores preditivos do que como fatores prognósticos ${ }^{(1,12,13,33)}$. No presente estudo, os três fatores preditivos mais frequentemente avaliados foram os receptores hormonais (RE e RP) e HER2, o que está de acordo com as recomendações da Conferência de Consenso de Saint Gallen (2005) $)^{(14)}$ para se instituir terapia adjuvante em câncer de mama.

A qualidade do processamento do material que antecede a realização dos testes imuno-histoquímicos (referida como fase pré-analítica) pode comprometer o resultado final da reação. Em 47 casos (3,6 \%) revistos em nosso estudo, não foi possível analisar a reação $\mathrm{IHQ}$, devido à autólise do material, à coloração citoplasmática inespecífica ou ao excesso de fixação. A fixação insuficiente ou por tempo excessivo afeta profundamente os resultados da IHQ. A reativação antigênica pode melhorá-los, mas não recupera tecidos com autólise ou com tempo excessivo de fixação(13, 17, 46, 48). Um estudo abordou o tempo mínimo necessário para fixação de tumores mamários antes da realização do exame imuno-histoquímico para $\mathrm{RE}^{(17)}$. Os autores concluíram que seriam necessários pelo menos 6 a 8 horas de fixação do tecido, previamente clivado, em formol tamponado antes da realização da IHQ. Por outro lado, o excesso de fixação encobrindo sítios antigênicos ou a falta de fixação adequada pela demora na clivagem do material produzindo autólise também podem ser responsáveis pela negatividade das reações para receptores hormonais ${ }^{(17,46,48)}$.

Em nosso estudo, a IHQ foi realizada em material obtido por biópsia por agulha em apenas $18,45 \%$ dos casos. Esse é um método diagnóstico muito utilizado em propedêutica mamária e propicia a rápida fixação dos tecidos ${ }^{(47)}$. A biópsia por agulha é de particular valor para avaliação de marcadores tumorais em tumores grandes, em pacientes que vão se submeter à quimioterapia neoadjuvante. Trabalhos que avaliaram a determinação de RE na biópsia por agulha versus espécime cirúrgico mostram índice de concordância de até $98,8 \%^{(10,20)}$. Nos casos discrepantes, a maior positividade é obtida nas amostras de biópsia por agulha, e não nos espécimes cirúrgicos, provavelmente devido à melhor fixação tecidual que ocorre nas amostras menores e ao rápido processamento. No entanto, a heterogeneidade tumoral e os erros de amostragem na biópsia por agulha também podem levar a alguma variação nos resultados ${ }^{(47)}$. Em nosso estudo, 23,1\% dos casos a IHQ foi realizada em amostras obtidas de espécimes cirúrgicos maiores, como mastectomia, sem a informação do tempo de permanência no fixador. A não-fixação do tumor, seja pelo menor tempo de exposição ao fixador, seja pela demora na clivagem do espécime, pode interferir nos resultados da IHQ ${ }^{(47)}$. Goldstein et al. ${ }^{(17)}$ observaram que a avaliação do RE é muito dependente do tempo de fixação, e que a fixação do tumor por tempo inferior a 6 a 8 horas afetava mais os resultados da IHQ do que a fixação excessiva, parcialmente revertida pela recuperação antigênica.

A qualidade final da reação depende, além da boa qualidade da fixação e do processamento do tecido (fase pré-analítica), da escolha dos anticorpos primários e do sistema de visualização (fase analítica). Estudos recentes da literatura e de nosso grupo mostram maior sensibilidade dos novos anticorpos monoclonais de coelho para avaliação de receptores hormonais e do HER2 em câncer de mama comparados aos monoclonais de camundongo ${ }^{(19,32,40,41)}$.O uso dos novos anticorpos de coelho aumenta a detecção de casos positivos para RE e tem melhor correlação com a resposta terapêutica ${ }^{(7)}$ Além dos novos anticorpos de coelho, o uso dos novos sistemas de polímeros não-biotinilados também permite melhor qualidade das reações com menos coloração inespecífica e sem os efeitos da biotina endógena ${ }^{(13)}$.

Os resultados do exame imuno-histoquímico em mama são dependentes também, além das fases pré-analítica e analítica, da análise dos resultados (fase pós-analítica). No presente trabalho, as reações para receptores hormonais e HER2 foram interpretadas com parâmetros aceitos durante o período da realização dos testes. No entanto, novos níveis de corte (porcentagem de células coradas e intensidade de coloração) para análise das reações desses marcadores foram sugeridos mais recentemente. O Consenso de Saint Gallen (2005) ${ }^{(14)}$ recomendou que os receptores hormonais devem ser avaliados empregando-se o sistema de escore proposto por Allred(1). São considerados positivos tumores com mais de $1 \%$ de núcleos marcados com intensidade moderada ou forte. A Conferência de Consenso do CAP e da Sociedade Americana de Oncologia Clínica (ASCO) determinou também mudanças na avaliação do HER2 ${ }^{(48)}$. A nova recomendação considera positivos os tumores com mais de $30 \%$ de células com coloração membranar forte, e não apenas $10 \%$ como recomendava o Herceptest. Os casos em que a coloração tem intensidade moderada são classificados atualmente como indeterminados, e deve ser realizado o exame pela técnica da hibridação fluorescente in situ (FISH) ou cromogênica (CISH) para confirmação da amplificação gênica ${ }^{(18,19,39,48)}$. Além do nível de corte, a experiência do patologista na interpretação das reações para o HER2 também é importante para melhorar a interpretação do teste e reduzir a variação entre observadores ${ }^{(31)}$. 
É possível que, utilizando esses novos escores para interpretação das reações, os nossos resultados também sofram modificações. Assim, na avaliação de fatores preditivos em câncer de mama, o controle de qualidade das fases pré-analítica, analítica e pós-analítica com atualização constante sobre novos reagentes e critérios de interpretação das reações são necessários, com repercussões importantes na decisão terapêutica dos pacientes ${ }^{(2,13,24,30,39,41)}$.

Na maioria dos casos de câncer de mama do nosso estudo, a avaliação IHQ foi realizada no tumor primário (85\% dos casos). É aceito que, quando os receptores hormonais são negativos no tumor primário, serão também nas metástases, e os pacientes não responderão à terapia endócrina (TE) ${ }^{(24)}$. Quando a amostra do tumor primário não está disponível para avaliação IHQ, é aceitável a realização do exame em metástases linfonodais. Dados da literatura indicam que há pouca diferença entre amostras tumorais do tumor primário e metástases em linfonodos regionais ${ }^{(47)}$. Os casos de conversão, ou seja, os receptores são negativos no tumor primário e positivos na metástase ou recidiva, têm sido considerados provavelmente como falso-negativos na avaliação inicial do tumor primário(24).

Há dúvidas com relação à ocorrência de mudanças na expressão de marcadores moleculares entre o tumor primário e a recorrência subsequente ou doença metastática, particularmente com o aumento do uso de tratamentos adjuvantes. Mudanças podem ocorrer na expressão de RE após resistência ao uso do tamoxifeno, com $15 \%$ a $20 \%$ dos cânceres, tornando-se negativos para RE. A redução no número de RP acontece após terapia hormonal (TH). Dúvidas existem com relação ao status do HER2 entre o tumor primário e a metástase a distância, tendo em vista o pequeno número de casos estudados ${ }^{(49)}$.

O nosso estudo avaliou 137 casos de linfonodo sentinela que foram negativos no exame histopatológico inicial (coloração pela hematoxilina e eosina). Em 13/137 casos (9,5\%), identificou-se a presença de células epiteliais metastáticas, tanto micrometástases (com dimensão entre 0,2 a $2 \mathrm{~mm}$ ) como células tumorais isoladas (dimensão $<0,2 \mathrm{~mm}$ ). A literatura relata taxas de detecção de micrometástases em $7 \%$ a $42 \%$ em linfonodos axilares, dependendo do método de estudo empregado ${ }^{(25-27,45)}$. Sabe-se que aproximadamente $25 \%$ dos pacientes linfonodo-negativos desenvolverão recidiva da doença e que poderiam talvez ter se beneficiado de quimioterapia adjuvante. Acredita-se que a recorrência seria devido às metástases que não foram detectadas pelos métodos de rotina e cujos pacientes foram subestadiados. Embora o exato significado clínico das micrometástases per- maneça incerto, estudos têm mostrado que está associado a linfonodos não-sentinela positivos em aproximadamente $10 \%$ a $30 \%$ dos casos, especialmente quando os tumores são maiores que $1 \mathrm{~cm}^{(4,25)}$. A presença de células epiteliais é descrita ainda nos seios subcapsulares e linfáticos de linfonodos axilares como transporte benigno ou passivo em pacientes submetidas a procedimentos prévios com agulha grossa ${ }^{(6)}$. Em nosso estudo, além da coloração positiva para citoqueratina consideramos também a topografia onde as células foram encontradas e o padrão morfológico das células positivas. Elas tinham morfologia epitelial e formavam pequenos ninhos, massas ou células isoladas, tratando-se de verdadeiras micrometástases ou células tumorais isoladas. Nesses casos, consideramos ainda a ausência de macrófagos contendo hemossiderina em torno das células epiteliais metastáticas.

Em nosso trabalho, o uso da IHQ para definição diagnóstica foi realizado em 51 casos. A IHQ contribuiu na definição diagnóstica, principalmente entre as lesões epiteliais proliferativas pré-malignas ou borderline $(45,1 \%)$ e nas lesões papilares $(25,5 \%)$ que representaram a maioria dos casos testados nesse grupo. Marcadores mioepiteliais foram empregados em nosso estudo na diferenciação entre CDIS e CDIS com microinvasão, na diferenciação entre lesão papilar benigna (papiloma e micropapiloma) e lesões papilares com atipia ou papilomas envolvidos por CDIS. Os marcadores mioepiteliais empregados foram aqueles descritos na literatura, incluindo actina de músculo liso, p63 e calponina ${ }^{(4,35,38,43,49)}$. Na diferenciação entre carcinoma ductal invasor (com artefatos de retração) e carcinoma micropapilar invasor, utilizamos o antígeno de membrana epitelial (EMA). O padrão de coloração pelo EMA na superfície epitelial voltada para o estroma é descrito nos carcinomas micropapilares, referido como polaridade invertida e foi identificado nos nossos casos com esse diagnóstico(4, 49).

Em nosso estudo, uma das principais indicações de IHQ no diagnóstico diferencial foi para auxiliar na distinção entre CDIS versus CDIS com microinvasão (sete casos, 13,7\%). Estudo anterior de nosso grupo já havia mostrado dificuldade entre os patologistas da nossa comunidade em realizar esse diagnóstico ${ }^{(42)}$. É comum o CDIS de alto grau estar associado à reação estromal com infiltrado inflamatório e neoformação vascular, dificultando a interpretação da lesão. Nesses casos, o uso de IHQ demonstrando as células mioepiteliais pode auxiliar no diagnóstico do CDIS. No entanto, deve-se tomar cuidado, pois há algumas limitações no uso desses marcadores. A marcação para p63, mesmo em hiperplasias epiteliais sem atipias, pode ser descontínua( ${ }^{(38,43,44)}$. A actina 
de músculo liso cora também miofibroblastos estromais associados às lesões e pode ser erroneamente interpretada como célula mioepitelial positiva ${ }^{(38,43)}$. Assim, cuidados na fixação do tecido, bom preparado histológico e teste imunohistoquímico bem feito são complementares, não devendo o diagnóstico ser baseado apenas na demonstração ou ausência de células mioepiteliais marcadas .

Na diferenciação entre CDIS sólido de baixo grau histológico versus neoplasia/carcinoma lobular in situ utilizou-se a E-caderina. A E-caderina é uma molécula de adesão expressa nos carcinomas ductais e geralmente não é expressa ou tem expressão reduzida nas neoplasias lobulares ${ }^{(15,29)}$. No entanto, a decisão diagnóstica não deve se basear apenas na negatividade para E-caderina, visto que até $15 \%$ das neoplasias lobulares in situ podem expressar esses marcadores ${ }^{(9)}$. O padrão citológico e a distribuição arquitetural (padrão de distribuição da lesão, envolvimento lobular predominante e disseminação pagetoide) devem ser também considerados no diagnóstico final(16).

O número médio de anticorpos empregados em nosso estudo foi de 3,2 anticorpos. Em estudos imuno-histoquímicos de patologia cirúrgica geral, habitualmente é usado maior número de anticorpos por caso, variando de 4,1 a $5,8^{(3)}$. Para o estudo dos fatores preditivos e prognósticos, empregamos em média 3,4 anticorpos e, para avaliação do linfonodo sentinela, utilizamos o que tem sido preconizado na literatura, ou seja, apenas o anticorpo monoclonal antipancitoqueratina ${ }^{(25,27,49)}$. Dados da literatura mostram que o número de anticorpos utilizados em IHQ aplicada a lesões e tumores mamários é menor que em outras áreas da patologia ${ }^{(3,4,13,27,49)}$. Nossos dados estão de acordo com a maioria dos estudos que orientam realizar pelo menos avaliação com receptores hormonais e HER2 ${ }^{(12-14)}$. O painel preditivo recomendado hoje pelo Consenso de Saint Gallen de 2005 inclui RE, RP e HER2 para todos os casos de câncer de mama, acrescido do Ki-67 nos casos de indicação de quimioterapia neoadjuvante ${ }^{(14)}$.

Ao avaliarmos a positividade do RE e RP em 1.093 casos, observamos que a associação mais frequente foi $\mathrm{RE}+/ \mathrm{RP}+$ em 624 casos (57\%), e a menos frequente foi RE-/RP+ em apenas 33 casos (3\%). Os nossos dados são semelhantes aos da literatura, que mostram raríssimos casos de tumores $\mathrm{RE}-/ \mathrm{RP}_{+}{ }^{(5,21)}$. A expressão do RP é induzida pelo RE, por isso a maioria dos tumores RP+ também é RE+. Programas de controle de qualidade sugerem que, quando o estudo imuno-histoquímico revelar tumor $\mathrm{RE}-/ \mathrm{RP}+$, deve-se repetir a análise para RE e, principalmente, melhorar a reativação antigênica $^{(20)}$.
Nossos resultados imuno-histoquímicos nos permitiram realizar a imunofenotipagem molecular dos 979 casos em que avaliamos RE, RP e HER2 e classificá-los como triplonegativos (21,8\%), luminal A $(60,2 \%)$, luminal B $(9 \%)$ e HER2+/RE- (9\%). Os nossos dados são semelhantes aos de Carey et al.(5) que avaliaram 496 casos e encontraram tumores triplo-negativos $(20,1 \%)$, luminal $A(51,4 \%)$, luminal B $(15,5 \%)$ e HER2+/RE- (6,6\%). Os estudos mostram que pacientes com tumores triplo-negativos e HER2+/RE- são mais sensíveis ao esquema de quimioterapia neoadjuvante com antracíclicos. Os pacientes com tumores triplo-negativos têm pior prognóstico quando comparados aos tumores luminais, o que pode ser explicado pela alta probabilidade de recidiva nas pacientes que não obtêm resposta patológica completa, parâmetro importante de resposta

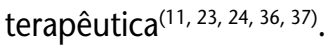

Estudos de expressão gênica usando microarranjos de DNA e de expressão protéica em microarranjos de tecidos identificaram um grupo de tumores mamários que expressam marcadores mioepiteliais, referidos por isto como carcinomas de fenótipo basal. Estes tumores, em geral, são triplo-negativos e de pior prognóstico ${ }^{(11,23,34,36)}$. No entanto, ainda não há consenso sobre quais marcadores devam fazer parte da avaliação IHQ para definição do câncer de fenótipo basal. Por isso, sua frequência é variável na literatura, podendo chegar a $50 \%$ dos casos avaliados ${ }^{(11)}$. Entretanto, os estudos concordam que devem fazer parte dessa avaliação pelo menos um entre os seguintes marcadores: CK5/6, CK14 ou CK17 ${ }^{(11,23,36,37)}$. No entanto, o emprego clínico rotineiro de marcadores de fenótipo basal ainda não está indicado, talvez pela ausência até o momento de tratamentos específicos para esses tumores. Com o rápido avanço das pesquisas nessa área, é possível que em breve novos alvos terapêuticos sejam identificados para esses casos e que a IHQ seja também incorporada na identificação desse subtipo tumoral.

No nosso estudo, observamos também que, quando correlacionamos os subtipos tumorais com idade (pré-menopausa ou pós-menopausa), todos os subtipos foram mais frequentes na pós-menopausa, mesmo os subtipos triplo-negativos de pior prognóstico. Diferentemente dos nossos resultados, Carey et al.(5) mostraram que os subtipos triplo-negativos e HER2+/RE- eram mais frequentes na pré-menopausa.

Concluindo, os nossos dados confirmam que o estudo imuno-histoquímico é importante ferramenta em patologia mamária para avaliação de fatores preditivos de resposta terapêutica, para pesquisa de micrometástases em linfonodo sentinela e para diagnóstico diferencial de lesões mamárias. 


\section{Referências}

1. ALLRED, D. C. et al. Prognostic and predictive factors in breast cancer by imnunohistochemical analysis. Mod Pathol, v. 11, n. 2, p. 155-68, 1998.

2. ALVES, V. A. F. et al. Controle de qualidade interlaboratorial em imuno-histoquímica: citoceratinas e receptor de estrógeno como modelos. J Bras Patol Med Lab, v. 40, n. 3, p.175-83, 2004.

3. BETINA, W. et al. Uso prático da imuno-histoquímica em patologia cirúrgica. J Bras Patol Med Lab, v. 41, n. 5, p.353-64, 2005.

4. BHARGAVA, R., DABBS D. J. Use of immunohistochemistry in diagnosis of breast epithelial lesions. Adv Anat Pathol, v. 14, n. 2, p. 93-107, 2007.

5. CAREY, L. A. et al. Race, breast cancer subtypes, and survival in the Carolina Breast Cancer Study. Jama, v. 295, n. 21, p. 2492-502, 2006.

6. CARTER, B. A. I. Benign transport of breast epithelium into axillary lymph node after biopsy. Am J Clin Pathol, v. 113, n.2, p. 259-65, 2000.

7. CHEANG, M. C.U. et al. Immunohistochemical detection using the new rabbit monoclonal antibody SP1 of estrogen receptor in breast cancer is superior to mouse monoclonal antibody 1D5 in predicting survival. J Clin Oncol, v. 24, n. 36, p. 5637-44, 2006.

8. DAKO. Dako Herceptest ${ }^{\mathrm{TM}}$ : a manual for interpretation. Carpinteria: Dako, Manual Guideline, 1999.

9. DA SILVA, L. et al. Aberrant expression of E-cadherin in lobular carcinomas of the breast. Am J Surg Pathol, v. 32, n. 5, p. 773-83, 2008

10. DOUGLAS-JONES, A. G. et al. Comparison of core estrogen receptor (ER) assay with excised tumour: intratumoral distribuition of ER in breast carcinoma. J Clin Pathol, v. 54, n. 12, p. 951-5, 2001.

11. FADARE, O., TAVASSOLI, F. A. The phenotypic spectrum of basal-like breast cancer: a critical appraisal. Adv Anat Pathol, v. 14, n. 5, p. 358-73, 2007.

12. FITZGIBBONS P. L. et al. Prognostic factors in breast cancer. College of American Pathologists Consensus Statement 1999. Arch Pathol Lab Med, v. 124, n. 7 p. 966-78, 2000.

13. GOBBI, H. et al. Preditive factors of breast cancer evaluated by imunohistochemistry. J Bras Patol Med Lab, v. 44, n. 2, p. 127-36, 2008.

14. GOLDHIRSCH, J. H. et al. Meeting highlights: international expert consensus on the primary therapy of early breast cancer 2005. Ann Oncol, v. 16, p. 1569-83, 2005.

15. GOLDSTEIN, N. S. et al. E-cadherin reactivity of 95 noninvasive ductal and lobular lesions of the breast. Implications for the interpretation of problematic lesions. Am J Clin Pathol, v. 115, n. 4, p. 534-42, 2001.

16. GOLDSTEIN, N. S. Does the level of E-cadherin expression correlate with the primary breast carcinoma infiltration pattern and type of systemic metastases? Am J Clin Pathol, v. 118, n. 3, p. 425-34, 2002.

17. GOLDSTEIN, N. S. et al. Minimum formalin fixation time for consistent estrogen receptor immunohistochemical staning of invasive breast carcinoma. Am J Clin Pathol, v. 120, n. 1, p. $86-92,2003$
18. GOUVÊA, A. P. et al. Her-2/neu immunoreactivity in invasive mammary carcinomas: a comparative study using monoclonal and polyclonal antibodies including the HercepTest ${ }^{\mathrm{TM}}$. J Bras Patol Med Lab, v. 40, n. 1, p. 27-32, 2004.

19. GOUVÊA, A. P. et al. Selecting antibodies to detect HER2 overexpression by immunohistochemistry in invasive mammary carcinomas. Appl Immunohistochem Mol Morphol, v. 14, n. 1, p. 103-8, 2006.

20. HODI, Z. et al. The reliability of assessment of estrogen receptor expression on needle core biopsy specimens of invasive carcinomas of the breast. J Clin Pathol, v. 60, n. 3, p. 299-302, 2007.

21. HUANG, W. Y. et al. Hormone-related factors and risk of breast cancer in relation to estrogen receptor and progesterone receptor status. Am J Epidemiol, v. 151, n. 7, p. 703-14, 2000

22. KESHGEGIAN, A. A., CNAAN, A. Proliferation markers in breast carcinoma. Mitotic figure count, S-phase fraction, proliferating cell nuclear antigen, Ki67 and MIB-1. Am J Clin Pathol, v. 104, n. 1, p. 429, 1995.

23. LIVASY, C. A. et al. Phenotypic evaluation of the basal-like subtype of invasive breast carcinoma. Mod Pathol, v. 19, n. 2, p. 264-71, 2006.

24. MANN, G. B. et al. Reliance on hormone receptor assay of surgical specimens may compromise outcome in patients with breast cancer. J Clin Oncol, v. 23, n. 22, p. 5148-54, 2005

25. MARINHO, V. F. Z. et al. Micrometástases de carcinoma da mama em linfonodos axilares: detecção por imunoistoquímica versus hematoxilina e eosina. J Bras Patol Med Lab, v. 40, n.2, p. 127-32, 2004.

26. MARINHO, V. F. Z. et al. Relationship between histologic features of primary breast carcinomas and axillary lymph node micrometastases: detection and prognostic significance. Appl Immunohistochem $\mathrm{Mol}$ Morphol, v. 14, n. 4, p. 426-31, 2006.

27. MARINHO, V. F. Z. et al. Marcadores moleculares em câncer de mama preditivos de metástases axilares. Rev Assoc Med Bras, v. 54, n. 3, p. 1-5, 2008.

28. MARINHO, V. F. Z. et al. Lymph vascular invasion in invasive mammary carcinomas identified by the endothelial lymphatic marker D2-40 is associated with other indicators of poor prognosis. BMC Cancer, v. 8, p. 1-9, 2008.

29. MASTRACCI, T. L. et al. E-cadherin alterations in atypical lobular hyperplasia and lobular carcinoma in situ of the breast. Modern Pathol, v. 18, n. 6, p. 741-51, 2005.

30. NONOGAKI, S. et al. Análise de indicadores internos e externos relevantes à resolutividade diagnóstica em laboratório de referência em imuno-histoquímica. J Bras Patol Med Lab, v. 43, n. 4, p. 297-304, 2007.

31. NUNES C. B. et al. Concordância interobservador na interpretação imuno-histoquímica da superexpressão do Her-2 detectada por cinco diferentes anticorpos em array de carcinomas mamários. J Bras Patol Med Lab, v. 43, n. 5, p. 373-9, 2007. 
32. NUNES, C. B. et al. Comparative analysis of six different antibodies against Her2 including the novel rabbit monoclonal antibody (SP3) and chromogenic in situ hybridisation in breast carcinomas. J Clin Pathol, v. 61, n. 8, p. 934-8, 2008.

33. PAGE, D. L. et al. Routinely available indicators of prognosis in breast cancer. Breast Cancer Res Treat, v. 51, n. 3, p. 195-208, 1998.

34. PAREDES, J. et al. P-cadherin and cytokeratin 5: useful adjunct markers to distinguish basal-like ductal carcinomas in situ. Virchows Arch, v. 450, n. 1, p. 73-80, 2007.

35. PINDER, T. C. etal. Breast pathology practice: most common problems in a consultation service. Histopathology, v. 47, n. 5, p. 445-57, 2005.

36. RAKHA, E. A. et al. Breast carcinoma with basal differentiation: a proposal for pathology definition based on basal cytokeratin expression. Histopathology, v. 50, n. 4, p. 434-8, 2007.

37. RAKHA, E. A. et al. Prognostic markers in triple-negative breast cancer. Cancer. v. 109, n. 1, p. 25-32, 2007.

38. RIBEIRO-SILVA, A. et al. Is p63 reliable in detecting microinvasion in ductal carcinoma in situ of the breast? Pathol Oncol Res, v. 9, n. 1, p. 20-3, 2003.

39. RICARDO, S. A. et al. HER2 evaluation using the novel rabbit monoclonal antibody $\mathrm{SP} 3$ and $\mathrm{CISH}$ in tissue microarrays of invasive breast carcinomas. J Clin Pathol, v. 60 , n. 9, p. 1001-5, 2007.

40. ROCHA, R. M. et al. A comparison between the novel rabbit monoclonal antibodies (SP1 and B644) and mouse antibodies for evaluating estrogen receptor in breast tumors. J Bras Patol Med Lab, v. 43, n. 6, p. 435-40, 2007.
41. ROCHA, R. et al. Rabbit monoclonal antibodies show higher sensitivity than mouse monoclonals for estrogen and progesterone receptor evaluation in breast cancer by immunohistochemistry. Pathol Res Pract, v. 204, n. 6, p. 655-62, 2008.

42. SALLES, M. A., et al. Variação interobservador no diagnóstico histopatológico do carcinoma ductal in situ da mama. Rev Bras Ginecol Obstet, v. 27, n. 1, p. 1-6, 2005.

43. SCHENKA, N. G. M. et al. p63 and CD10: Reliable markers in discriminating benign sclerosing lesions from tubular carcinoma of the breast? Appl Immunohistochem Mol Morphol, v. 14, n. 1, p. 71-7, 2006.

44. TAFURI, L. S., ROCHA, G. F., GOBBI, H. Cell cycle related proteins in hyperplasia of usual type in breast specimens of patients with and without breast cancer. BMC Cell Biol, v. 7, p.1-8, 2006.

45. TAN, L. K. et al. Occult axillary node metastases in breast cancer are prognostically significant: results in 368 node-negative patients with 20-year follow-up. J Clin Oncol, v. 26, n. 11, p. 1803-9, 2008.

46. TAYLOR, C. R. Standardization in immunohistochemistry: the role of antigen retrieval in molecular morphology. Biotech Histochem, v. 81, n. 1, p. 3-12, 2006.

47. WALKER, R. A. Immunohistochemical markers as predictive tools for breast cancer. J Clin Pathol, v. 61, p. 689-96, 2008.

48. WOLFF, A. C. et al. American Society of Clinical Oncology/College of American Pathologists Guideline Recommendations for Human Epidermal Growth Factor Receptor 2 Testing in Breast Cancer. J Clin Oncol, v. 25, n. 1, p. 118-45, 2007.

49. YEH, T., MIES, C. Application of immunohistochemistry to breast lesions. Arch Pathol Lab Med, v. 132, n. 3, p. 349-58, 2008. 